\title{
Creating Pathways to Stackable Credentials in Robotics: Meeting Industry Needs by Manufacturing a Community College and University Partnership
}

\author{
Mr. Mark Bradley Kinney, Bay de Noc Community College
}

Mark Kinney became the Executive Dean for Business, Technology, and Workforce Development in July of 2012, but first came to Bay College as the Executive Director of Institutional Research and Effectiveness in February 2009. Prior to that, Mark served as the Dean for Computer Information Systems and Technology at Baker College of Cadillac and as the Chief Operating Officer and network administrator at Forest Area Federal Credit Union. He has taught a wide range of courses in the computer information systems discipline and holds certifications in both Microsoft Excel and Microsoft Access. Mark has a Master's in Business Administration with a concentration in Computer Information Systems from Baker College, as well as a Bachelor's in Business Leadership and an Associate's of Business from Baker College. Currently, Mark is completing his dissertation in fulfillment of the requirements of a Doctorate in Educational Leadership from Central Michigan University.

Prof. Aleksandr Sergeyev, Michigan Technological University

Aleksandr Sergeyev is currently an Associate Professor in the Electrical Engineering Technology program in the School of Technology at Michigan Technological University. Dr. Aleksandr Sergeyev earned his bachelor degree in Electrical Engineering at Moscow University of Electronics and Automation in 1995. He obtained the Master degree in Physics from Michigan Technological University in 2004 and the $\mathrm{PhD}$ degree in Electrical Engineering from Michigan Technological University in 2007. Dr. Aleksandr Sergeyev's research interests include high energy laser propagation through the turbulent atmosphere, developing advanced control algorithms for wavefront sensing and mitigating effects of the turbulent atmosphere, digital inline holography, digital signal processing, and laser spectroscopy. Dr. Sergeyev is a member of ASEE, IEEE, SPIE and is actively involved in promoting engineering education.

\section{Prof. Scott A Kuhl, Michigan Technological University}

Scott Kuhl is an Assistant Professor of Computer Science and an Adjunct Assistant Professor of Cognitive \& Learning Sciences at Michigan Technological University. He received his Ph.D. in Computer Science from the University of Utah in 2009. His research interests include immersive virtual environments, headmounted displays, and spatial perception. A link to his web page can be found at http://www.cs.mtu.edu/.

\section{Mr. Mark Norman Highum, Bay College}

Mark Highum is currently the Division Chair for Technology at Bay College. He is the Lead Instructor for Mechatronics and Robotics Systems and also teaches courses in the Computer Network Systems and Security degree. Mark holds a Master's in Career and Technical Education (Highest Distinction) from Ferris State University, and a Bachelor's in Workforce Education and Development (Summa Cum Laude) from Southern Illinois University. Mark is a retired Chief Electronics Technician (Submarines) and served and taught as part of the Navy's Nuclear Power Program. Mark is active with SkillsUSA and has been on the National Education Team for Mechatronics since 2004. 


\title{
Creating Pathways to Stackable Credentials in Robotics: Meeting Industry Needs by Manufacturing a Community College and University Partnership
}

\begin{abstract}
Especially in rural locales like Michigan's Upper Peninsula, students and employers alike can struggle in their search to find STEM-based educational opportunities and the qualified graduates that result from them. Thanks to an innovative partnership between Bay de Noc Community College and Michigan Technological University, however, students are being provided with new opportunities to receive a quality education in the fields of mechatronics and robotics. By codeveloping robotics curriculum and partnering on a number of grant applications to procure equipment, Bay de Noc Community College (commonly known as Bay College) and Michigan Tech have created a replicable student pathway that can result in a certificate in mechatronics, an associate's degree in mechatronics and robotic systems, and a bachelor's degree in electrical engineering technology.
\end{abstract}

This pathway could not come at a better time, as the International Federation of Robotics (IFR) projects 1.9 to 3.5 million jobs related to robotics will be created in the next eight years. In order to help meet this employer demand, Bay College and Michigan Tech have developed state-ofthe-art training labs featuring FANUC robots and articulation agreements between the institutions that will allow students to begin pursuing a high-tech education and career as early as high school. Furthermore, stand-alone programs are being developed to train and certify students from other institutions, industry representatives, and other educators; a new robotic simulation software known as "RobotRun" is being developed to aid in instruction; and a variety of workshops aimed at K-12 teachers and students, industry personnel, and other postsecondary educators will be offered. Resources and best practices that have resulted from this partnership will be shared widely in order to help others around the country replicate this innovative pathway that provides students with a quality education and employers with STEM graduates who are ready for the workforce.

\section{Introduction}

In the Upper Peninsula of Michigan, colloquially known as the U.P., postsecondary educational opportunities are somewhat limited. The U.P. is 16,538 square miles, making it larger than Massachusetts, Connecticut, Delaware, and Rhode Island combined, but is only served by two community colleges ${ }^{9}$. Despite its large size, however, the U.P. has a population of only just over 300,000 people 9 . This means that the land itself represents $29 \%$ of Michigan's total area, but only $3.3 \%$ of its population ${ }^{3}$. While this low population density makes for beautiful countryside and bountiful outdoor recreational opportunities, it can also be challenging for both prospective students looking for an education and employers in search of new talent.

Serving the south-central portion of the U.P. is one of the region's two public community colleges. Officially titled Bay de Noc Community College, but commonly referred to simply as 
Bay College, this small institution of just over 1,700 students offers a wide variety of programs designed to either help students transfer to a university or enter the workforce directly. Founded in 1962, Bay College now offers programs in welding, water resource management, computer network systems and security, geographic information systems, business, office information systems, criminal justice, early childhood education, automotive technology, and many others. Each of these occupational programs were specifically chosen due to their direct connection to available jobs in the community and the surrounding region. By working closely with area employers, Bay College faculty and administration have a long history of identifying talent needs and developing relevant academic programming in response.

In recent years, however, a challenge seemed to present itself. Employers frequently called for qualified graduates in the field of advanced manufacturing, yet there seemed to be no consistency between employers in the specific skill sets being sought. One employer would talk of the need for new employees possessing a knowledge of electricity, while another desired hydraulics and pneumatics. Still others had moved on towards automation technologies and desired graduates with entry-level skills in robotics. Even within other industries, such as those typically targeted by the water resource management program, employers were asking for new skill sets in areas like process control, as well as supervisory control and data acquisition (SCADA). Despite the obvious need for curriculum to supply graduates to this industry, however, Bay College could not possibly support programs in each of these areas due to its small size and limited resources. Thus, for years, the requests of these employers went unmet.

It was not until October of 2013 that an idea for a potential solution began to form. During a visit to Michigan Technological University in Houghton, MI, the dean for the business and technology programs at Bay College, Mark Kinney, met with two Michigan Tech faculty members who had been contracted to perform some work under Bay College's recently awarded grant from the Trade Adjustment Assistance Community College and Career Training (TAACCCT) program under the Department of Labor. One of these faculty members was the Associate Professor in the Electrical Engineering Technology (EET) program at Michigan Tech, Aleksandr Sergeyev. While he provided a tour of the EET lab, he described a grant opportunity that might allow Bay College to not only obtain much of the equipment they would need to create an academic program designed to meet their area employers' advanced manufacturing needs, but could also be used to create a partnership between the two schools that would lead to coordinated curriculum and an articulation agreement between Bay College's program and that of Michigan Tech. A year later that grant application was written and subsequently funded, allowing the two schools to pursue their development of a pathway to stackable credentials in robotics.

\section{An Overview of the Program}

Even with grant funding, creating separate academic programs to meet each of the diverse requests from area employers was impractical. Instead, Bay College and Michigan Tech aimed to create a single program that contained elements of each request. For instance, rather than creating an entire program surrounding the need for manufacturers with an electrical background, and yet another program focusing on hydraulics and pneumatics, a single program would be created that included introductory coursework in each of these areas and more. Under this model, students could get a single certificate or associate's degree and obtain employment in 
a variety of industries. Furthermore, individual courses could then be integrated into other academic programs where those skills were being requested, such as including a basic process control course in the water resource management program.

Since certain industry positions required only entry level skills, while others required a greater depth or breadth of knowledge and abilities, a stackable credentials model was used. Under this model, students can earn a certificate in mechatronics, which is a one-year program containing a variety of introductory courses in several advanced manufacturing fields. Students can then either enter the workforce directly or can stack an associate's degree on top of their certificate by extending their studies for another year, thereby gaining additional training in robotics and automation technologies, as well as picking up general education coursework. At this point, students once again have the option of entering the workforce directly or, thanks to the articulation agreement, transferring their associate's degree to Michigan Tech's EET bachelor's degree program. The program thus has three separate credentials that can be stacked atop each other either during a student's initial entry into college or as they decide to pursue additional education after gaining direct experience in the workforce.

In addition to the development of academic programs, several other educational options are also being created as part of this partnership. The first of these is to provide stand-alone, non-credit workshops to train and certify students from other institutions, industry representatives, and displaced workers. Workshops will also be created to train educators at both the K-12 and postsecondary levels on the use of FANUC robots and the role the field of robotics plays in STEM education. This activity is aimed at broadening the scope of the project beyond just Bay College and Michigan Tech through improving the quality of industrial robotics education at other area institutions. Thanks to the attainment of FANUC Certified Education Training by Bay College's full-time faculty member overseeing the program, Mark Highum, Bay College and Michigan Tech will also now be able to offer reciprocal certification opportunities to attendees of these events. Lastly, robotic simulation software known as RobotRun is being developed to assist students in learning the basics of how to program robotic arms. More detailed information on each element of this project is contained in the following sections.

\section{Mechatronics}

According to a Manpower Group survey of nearly 42,000 employers across 42 countries, technicians, production operators, and engineers are both listed among the top ten jobs that are currently the most difficult to fill on a global scale ${ }^{5}$. Within the Americas specifically, each of these positions are also listed among the top ten, with the notable addition of skilled trades workers coming in at the \#1 most difficult position to fill ${ }^{5}$. Furthermore, a 2015 report by the Association for Talent Development found that employers spent an average of \$1,229 per employee on training in $2014^{1}$, while the replacement rate on positions in the electrical engineering field has historically stood at an astounding $23 \%{ }^{2}$. The combination of this high turnover, high training costs, and difficulty in finding qualified employees leads to a dire situation in the skilled trades field. For these reasons, which have been corroborated by local employers in desperate search of talent, Bay College chose to develop a mechatronics certificate and associate's degree. 
Mechatronics is a term that is becoming very popular at many levels of education. There are graduate, undergraduate, technical, and even secondary-level programs and degrees that are all aimed at training engineers and technicians for the field of mechatronics. The rapid growth of this new field may lead some people to wonder if it is truly a valid field of study or just a passing fad, but while the term mechatronics is not very familiar to most, it is not actually a new term. The word was created by Tetsuro Mori, an engineer at the Yaskawa Electric Corporation in Japan $^{8}$. There is no definitive date of when the word was first used, but the company applied for a trademark for the term in 1969. The trademark was eventually approved, but later released by the company, thus allowing for the term to become freely used throughout the world. Today, Yaskawa is a manufacturer of servo motors, AC motor drives, and other motion control devices, and their Motoman robots are used in a wide variety of industrial applications. It is this wide range of products that helps to define what is meant by the term mechatronics. While there are many slight variations in existence, mechatronics is generally considered to be a combination of mechanical, electronic, computer, and control systems. The figure below illustrates the intersection of these various fields into the single concept of mechatronics.

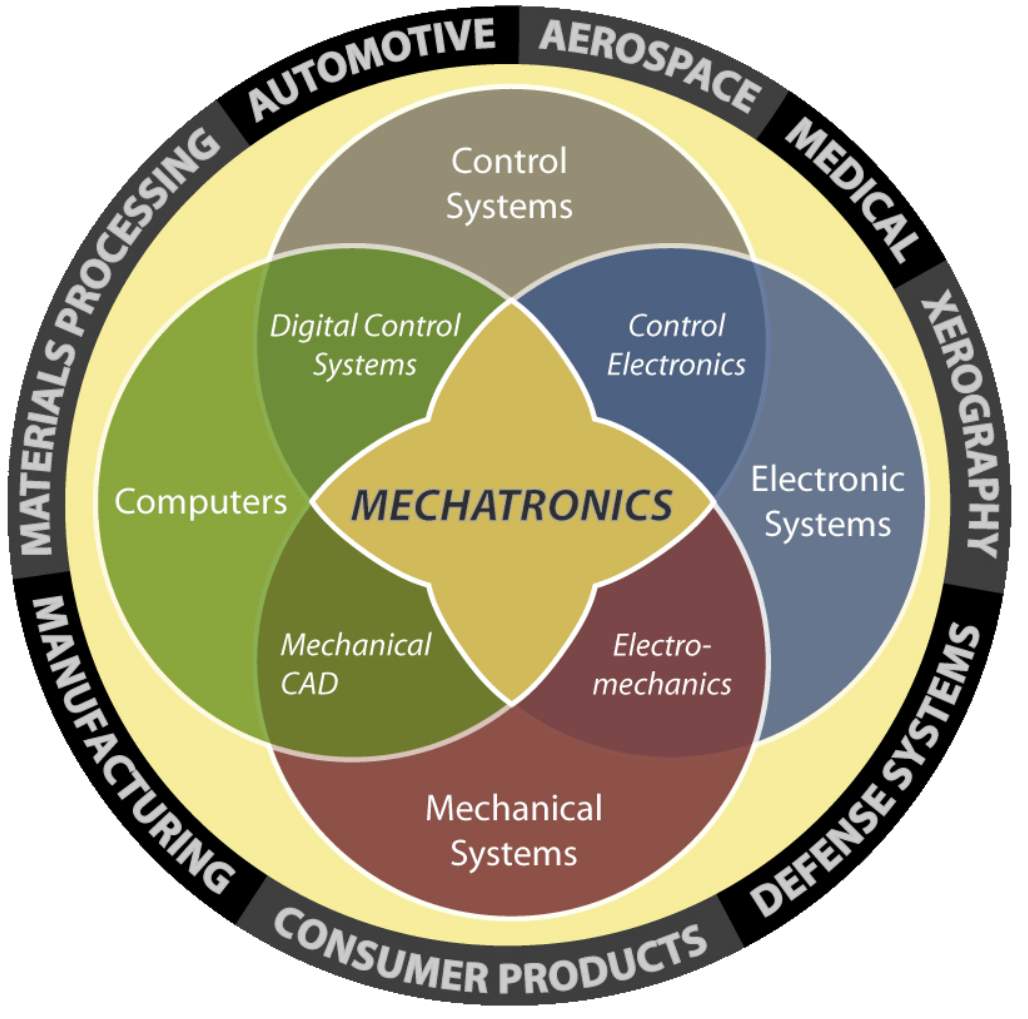

Fig. 1 - The many subfields of mechatronics ${ }^{6}$

Given the broad combination of technologies that make up mechatronics, it is hard to find any modern technical process that does not fall within the purview of the field. For instance, a computer using a traditional hard drive or DVD drive is itself a mechatronic system due to its combination of computer, electronic, and mechanical systems. A tablet may be totally solid state, but once a document is sent from that device to a printer, the introduction of the mechanical system creates an overall system of mechatronics. 
At Bay College, this wide range of included technologies is what made mechatronics such a promising solution to the problem of finding a single degree program that could meet the needs of diverse employer groups. During its first year as a certificate program, coursework included Circuit Fundamentals I, Fluid Power, Basic Machine Tool Operation, Basic Process Control, Electrical Machinery and Controls, and Introduction to Programmable Logic Controllers. Furthermore, thanks to the successful grant application with Michigan Tech, as well as other grants the college has successfully obtained, the mechatronics lab is now stocked with the following pieces of equipment:

Festo Learnline Stations (6) - These are training stations that allow flexible configuration of the equipment in a wide variety of locations. Bay College has equipment sets that include basic and advanced pneumatics, basic and advanced electro-pneumatics, basic and advanced hydraulics, and basic and advanced electro-hydraulics. Additionally, the electrical controls are compatible with $24 \mathrm{vdc}$ programmable logic controllers for automated control of the components.

Festo Modular Production Systems (10 stations) - Each station is a portion of an assembly line that performs different types of industrial processes on reusable work pieces. These processes include pick and place part movement, component testing, component assembly, and sorting components by material and color. The stations will function individually or as a complete production line. Each station is controlled by a programmable logic controller.

Festo Compact PCS Systems (3 stations) - These systems teach process control of pressure, level, temperature, and flow. The systems can be controlled by a touch screen panel and PLC or by computer interface. Multiple types of loop processes are possible, including two point control, proportional, integral, differential, and PID loops.

Depco Industrial Motor Control Trainers (2) - These trainers include a NEMA motor control cabinet and the ability to build to print, including wiring. Several types of motors are included to allow for investigation of properties of DC and AC motors.

FANUC LR Mate 200 Robots with 2D vision (6) - These carts allow for teaching students to safely energize and jog a robot, teach robot positions, master the robot, write and edit programs, and save and manipulate files. The vision system is used to teach how vision systems can be used to complement autonomous robot operation. The carts are obtained through the FANUC Cert program, so students will also receive FANUC certification.

Festo MecLabs (3 sets) - The MecLabs are table top versions of the Modular Production System stations. Each set contains one distribution station, one conveyor, and one assembly station. Each station can run by itself or in concert with the other stations. They are designed for use with FluidSim software, which creates circuits and also acts as the controller. Small and portable, they can be used in almost any classroom. They are also very useful for demonstrations of mechatronic principles.

These pieces of equipment, along with the aforementioned curriculum, provided a solid introduction to a wide range of advanced manufacturing skill sets. In meeting with employers, however, it quickly became apparent that even more diversity was needed. For example, while one employer lauded the inclusion of the Basic Machine Tool Operation course, others felt that 
would be a wasted skill set in their particular business. Instead, they wanted, for example, a blueprint reading course. Therefore, beginning in the Fall of 2016, the mechatronics certificate will now include several elective choices, allowing students to tailor their specific certificate program to the needs of the employer they may be pursuing. An overview of this certificate, including a complete list of the courses that comprise it, can be found by visiting http://baycollege.edu/BayCollege/media/Academics/Areas\%20of\%20Study/CertificateMechatronics-15-16.pdf.

\section{Robotics}

Despite the development of the mechatronics certificate, a need still existed for more advanced skills in advanced manufacturing and automation. Many existing jobs will be automated in the next 20 years, and robotics will be a major driver for global job creation over the next five years. These trends are made clear in a study conducted by the market research firm, Metra Martech ${ }^{4}$. Many repetitive, low-skilled jobs are already being supplanted by technology. However, a number of studies have found that in the aggregate, the robotics industry is creating more jobs than the number of jobs lost to robots. For example, the International Federation of Robotics (IFR) estimates that robotics directly created 4 to 6 million jobs through 2011 worldwide, with the total rising to eight to 10 million if indirect jobs are counted ${ }^{7}$. From 2014 to 2016 , robot installations are estimated to increase about $6 \%$ a year, resulting in an overall 3 -year increase of $18 \%{ }^{7}$. Likewise, industrial robot manufacturers are reporting $18-25 \%$ growth in orders and revenue year on year. While some jobs will be displaced due to the increased rollout of robots in the manufacturing sector, many will also be created as robot manufactures recruit to meet growing demand. Furthermore, jobs that were previously sent offshore are now being brought back to developed countries due to advances in robotics. For example, Apple now manufactures the Mac Pro in America and has spent approximately $\$ 10.5$ billion in assembly robotics and machinery ${ }^{4}$. In March 2012, Amazon acquired Kiva Systems, a warehouse automation robot, and in 2013 deployed 1,382 Kiva robots in three Fulfillment Centers. This initiative has not reduced the number of employees at Amazon; in fact, it added 20,000 full-time employees to its US fulfillment centers alone.

Such rapid growth of robotic automation in all sectors of industry requires an enormous number of technically sound specialists with the skills in industrial robotics and automation to maintain and monitor existing robots, enhance development of future technologies, and educate users on implementation and applications. This is why Bay College and Michigan Tech decided to codevelop robotics curriculum for use in an associate's degree in mechatronics and robotic systems. This degree will first be unveiled during the Fall of 2016 and will include coursework above and beyond that found in the mechatronics certificate, including Real-time Robotics Systems and Robotic Vision Systems. Students who complete the mechatronics certificate can choose to add these additional courses, as well as a complement of general education courses, to earn an associate's degree. To complete the pathway of stackable credentials, this degree can then be transferred to Michigan Tech's EET bachelor's degree program. An overview of this associate's degree, including a complete list of the courses that comprise it, can be found by visiting http://baycollege.edu/BayCollege/media/Academics/Marketing\%20pages/MechatronicsRobotics-AAS.pdf. 


\section{Non-Credit Workshops}

In addition to the for-credit certificate and degree programs that have been created by this partnership, a variety of non-credit workshops are also being developed. These workshops will be aimed at industry workers, K-12 educators, other postsecondary educators, and students from institutions outside of Bay College and Michigan Tech. Four different certifications will be provided as part of this project:

Certification 1: Handling Tool Operation and Programming (32-hour course) - This course is designed to be both practical and progressive. The content offers easily applied guidance to personnel involved in manufacturing with current robotic systems on site, or who may be asked to engage in implementing robotic systems in the near future. The course includes a discussion of scholarly and practical robotic topics ranging from kinematics and programming to practical application areas and economic concerns. Hands-on experience is an essential part of this course and will occupy $70 \%$ of course time.

Certification 2: Roboguide - Robotic Workcell Assembly (8-hour course) - FANUC Roboguide software is widely used in industry; therefore, there is a great need to train workers in this software. This 8-hour training course provides participants with a foundation for understanding all software features. By the end of the course, students assemble a fully functional virtual robotic workcell that includes the robot, end-effector, several fixtures, and industrial parts that the robot can manipulate. Students program the robot to execute a pick and place operation, run simulation in step-by-step and production modes, and compile a file that can be further transmitted to the physical FANUC robot for real-time production.

Certification 3: Robot Operations (16 hours) - There is a great demand in the industrial sector for robot operators that don't necessarily need to have very in-depth programming and theoretical skills. This course is intended for the person who operates or may be required to perform basic maintenance on FANUC robots via the standard application software package. It will teach students how to safely power up, power down, jog the robot to predefined positions, and set up different frames of operation. In addition, it will cover tasks and procedures needed to recover from common program and robot faults, and teach basic programming skills.

Certification 4: iR-Vision 2D (32-hour course) - Nearly any robot currently used in industry is equipped with a vision system. Vision systems are being used increasingly with robot automation to perform common and sometimes complex industrial tasks, such as: part identification, part location, part orientation, part inspection, and tracking. In other words, the vision system is the robot's eyes, which are needed to perform complex manufacturing tasks. This new course will teach students how to set up, calibrate, teach, test, and modify iRVision applications using FANUC robots. The course will include detailed discussion of hardware and software setup, establishing the communication link between the robot and teaching computer, teaching single- and multi-view processes, and programming. Safety procedures will be integrated into all exercises. The course will culminate in a certification exam in which the participants will have to demonstrate an understanding of the theoretical background, as well as the ability to successfully set up, calibrate, program, and utilize the FANUC robot equipped vision system. Participants passing the exam will receive a certificate in iRVision $2 D$ issued by a FANUC certified instructor. 
In addition to these workshops, training opportunities will also be targeted to other educators and students outside of Bay College and Michigan Tech. Faculty members will promote robotics automation to K-12 teachers and high school students by holding one-day seminars for K-12 teachers. During the seminar, participants will: 1) learn concepts of industrial robotics; 2) learn the basics of programming FANUC industrial robots; 3) try the robotic software "RobotRun"; and 4) work with faculty to consider ways the software can be integrated into the K-12 curriculum. Participating teachers will be provided with four hours of theory and four hours of hands-on operating and programming with FANUC robots and the "RobotRun" simulation software. To promote the field of robotics directly among the high school students, one "day camp" will be conducted yearly, at both institutions. Students will: 1) learn basic principles of industrial robots; 2) operate and program FANUC industrial robots; and 3) utilize the gaming environment of the "RobotRun" simulation software to play embedded games and conduct basic programming tasks. Due to the remote location of Upper Peninsula schools, very few programs targeting STEM fields are currently available. The proposed camps will provide high school students with the extraordinary opportunity to learn and get engaged in STEM-related activities using the appealing nature of robotics. This early-age engagement in STEM activities will help to create a clear path for the students to continue education through postsecondary institutions.

\section{RobotRun Software}

The final piece of this partnership between Bay College and Michigan Tech involves the development of an engaging, free, and open-source robotic training software aimed at helping students learn the basics of programming robotic arms. The software will act as a simulator where a user can write a program and then view how that program performs when run on a virtual 3D robotic arm displayed on the screen. Although robotics play an essential role at a variety of manufacturing facilities, there is currently no accessible and free software that can give students the opportunity to learn about using the robotic hardware without purchasing expensive, complex, proprietary software packages. The RobotRun software will show a 3D, animated rendering of a robotic arm that can be controlled via an intuitive programming language that is similar to the programs used to program real robotic arms. The programming language in the robotic arm simulator software will provide all of the basic commands that exist in real-world robotics systems so that students can easily transfer the knowledge gained from the developed software to real-world robotic arms. The software will allow the user to control where the end-effector should jog, at what speed and type of motion termination, how many times it should repeat the movement, and other common robotics controls. Besides the option of jogging the robot and performing programming tasks, the software will be configured to present users with different scenarios that mimic real-world industrial scenarios such as pick and place, palletizing, welding, and painting. The program will also allow users to load and save their programs so that they can turn them in to an instructor for grading.

The new software will provide all options necessary to teach the required skills in robotics handling tool operation and programming. It will be simple, without features of expensive robotic simulation software packages that are designed for in-depth industrial simulations and are not typically used in educational settings. The open-source and free nature of the developed RobotRun training software will have a significant and broad impact by: 1) enabling institutions unable to obtain expensive industrial robots to adapt and teach the developed robotics courses; 2) providing K-12 teachers with the opportunity to promote STEM education to students by 
introducing the appealing concept of robotics via an interactive training environment, at no cost to K-12 institutions; and 3) providing displaced workers wanting to improve their robotics skills with an intuitive, interactive, and complete tool to succeed.

\section{Initial Results and Next Steps}

Being that 2015-16 is the first year of the new mechatronics certificate, initial student enrollment numbers are low. During the Winter 2016 semester, five students had declared either the mechatronics certificate or the mechatronics and robotic systems associate degree as their major. However, due to the inclusion of the new Basic Process Control course as a required class in Bay College's water resource management program, a total of 37 students were enrolled in that course across two sections during this same semester. Furthermore, a total of 17 students took the new Circuit Fundamentals I course during the fall due to it being offered online and made available to interested dual-enrolled high school students. During the upcoming Fall 2016 semester, the second year of courses (for the new mechatronics and robotic systems associate's degree) will be offered for the first time, provided sufficient enrollment numbers are met. Students in this new program will continue to be tracked each successive year to determine how many enroll, how many progress through the different degree options, how many successfully transfer to Michigan Tech, and how many go on to achieve gainful employment as a result of their participation in the program.

As far as the other project deliverables, K-12 and industry workshops have begun to be developed, with the first one to be held at Michigan Tech on May 7. The RobotRun software has also largely been completed and is undergoing testing and final development. This software will be made available in the near future both as part of the non-credit workshops and academic programming.

\section{Conclusion}

Perhaps the most important aspect of this partnership between a community college and a university is the portability of this same idea to other institutions across the country. While the obtainment of a grant helped to purchase the equipment needed to set up a mechatronics lab at Bay College, there really are not any barriers to prevent other community colleges and universities from duplicating this type of partnership elsewhere. This is especially true considering the willingness of both Bay College and Michigan Tech to share resources, including the RobotRun simulation software.

From a student perspective, the development of this curriculum and the associated articulation agreement provides an important opportunity to receive an education and obtain employment in a variety of industries. This is important given the remote nature of the U.P., since students living in Escanaba might not otherwise have the means to earn a degree from Michigan Tech (a full three-hour drive away). The stackable nature of these credentials, as well as the non-credit workshops being developed, will allow individuals to slowly build their credentials as they gain industry experience or to complete the entire sequence before they begin their initial job search. In either case, by making these resources available and sharing the concepts described in this paper, Bay College and Michigan Tech hope to encourage other community colleges and universities to form similar partnerships around the country. 


\section{Bibliography}

${ }^{1}$ Association for Talent Development. (2016). State of the industry. Retrieved from Association for Talent Development: https://www.td.org/Professional-Resources/State-Of-TheIndustry-Report

${ }^{2}$ Deek, F. P., Kimmel, H., \& McHugh, J. (1998, July). Pedagogical changes in the delivery of the first course in computer science: Problem solving, then programming. Journal of Engineering Education, 87(3), 313-320.

${ }^{3}$ Delta Chamber of Commerce. (2016, May 2). About our area. Retrieved from Delta Chamber of Commerce: http://www.deltami.org/?aboutourarea

${ }^{4}$ Hughes, N. (2013, November 13). Apple investing record $\$ 10.5$ billion in supply chain robots \& machinery. Retrieved from Apple Insider: http://appleinsider.com/articles/13/11/13/apple-investing-record-105-billion-on-supplychain-robots-machinery

${ }^{5}$ ManpowerGroup. (2014). Talent Shortage Survey - 2015. Retrieved from ManpowerGroup: http://www.manpowergroup.com/talent-shortage-explorer/\#.VydtMD fQpF

6 "Mecha workaround" by original image: Ahm2307vectorization: Own work - Own work, based on File:Mecha.gif. Licensed under CC BY-SA 3.0 via Wikimedia Commons https://commons.wikimedia.org/wiki/File:Mecha workaround.svg\#media/File:Mecha w orkaround.svg

${ }^{7}$ Metra Martech. (2011, February 21). Positive impacts of industrial robots on employment. London, England.

${ }^{8}$ Townsend, N. (2013, April 30). Machine builders use mechatronics. Retrieved from Mechatronic tips: http://www.mechatronictips.com/2013/04/2913/technology/automation/machinebuilders-use-mechatronics/

${ }^{9}$ Upper Peninsula Travel and Recreation Association. (2016). Michigan's Upper Peninsula: Choose Your Path. Retrieved from Upper Peninsula Travel and Recreation Association: http://www.uptravel.com/groups-24/\#sect-62 